\title{
Long term amphetamine treatment improved behaviour in children with attention deficit hyperactivity disorder
}

\author{
Gillberg C, Melander H, von Knorring A-L, et al. Long-term stimulant treatment of children with attention-deficit hyperactivity \\ disorder symptoms. A randomized, double-blind, placebo-controlled trial. Arch Gen Psychiatry 1997 Sep;54:857-64.
}

\section{Question}

In children with attention deficit hyperactivity disorder (ADHD), can long term stimulant treatment improve behaviour?

\section{Design}

Randomised, double blind, placebo controlled trial with 18 months follow up.

\section{Setting}

4 university departments of child and adolescent psychiatry in Sweden.

\section{Patients}

72 children $6-11$ years of age who met $\geqslant 8$ of the 14 DSM-III-R criteria for ADHD. Exclusion criteria were IQ $<50$, chronic medical conditions, receiving ongoing medication (except for epilepsy), height 2 standard deviations below the norm, major psychosocial problems, or a history of alcohol or drug abuse in the patient or the principal caretaker. 62 patients (mean age $9 \mathrm{y}$, $82 \%$ boys, $42 \%$ with comorbid diagnosis) were randomised. 10 patients were withdrawn before randomisation.

\section{Intervention}

Initially, all patients participated in single blind amphetamine treatment for 3 months. Dosage was titrated from $5 \mathrm{mg}$ twice daily to an optimal level (maximum $60 \mathrm{mg}$ /day). 32 patients were allocated to the amphetamine group and 30 to the placebo group. After 12 months of randomised treatment patients received single blind placebo treatment for 3 months.

\section{Main outcome measures}

Level of inattentiveness, hyperactivity, and disruptive behaviour (Conners Teacher and Parent Rating Scales); score on the Wechsler Intelligence Scale for Children-Revised (WISC-R); treatment failure rate; and adverse effects.

\section{Main results}

All 62 children improved during the single blind amphetamine treatment period on the Conners Parent (mean score dropped by $27 \%$ ) and Teachers Rating Scales (mean score dropped by $47 \%$ ). These reductions in inattention, hyperactivity, and other disruptive behaviour were maintained in the amphetamine group but not in the placebo group 12 months after randomisation ( $\mathrm{p}<0.01)$. WISC-R scores increased (mean 4.5) in the 35 children taking amphetamine for $\geqslant 9$ months but remained unchanged in the 8 children who took placebo for $\geqslant 6$ months ( 1 tailed $\mathrm{p}<0.05$ ). Adverse effects were infrequent and, with the exception of decreased appetite in the amphetamine group, did not differ between the groups. Treatment failure was lower $(29 \%$ $v 71 \%, \mathrm{p}<0.001)$ and dropouts occurred later in the amphetamine group including children with comorbid diagnoses.

\section{Conclusion}

Long term amphetamine treatment reduced inattentive, hyperactive, and disruptive behaviours in children with attention deficit hyperactivity disorder.

Sources of funding: National Corporation of Swedish Pharmacies and Swedish Medical Research Council.

For correspondence: $\operatorname{Dr} C$ Gillberg, Department of Child and Adolescent Psychiatry, University of Göteborg, Annedals Clinics, $S 41345$ Göteborg, Sweden. Fax +4631415545 .

\section{Commentary}

In Europe there is still controversy, fuelled by the media, among health and education professionals and the public about whether we are under treating or over treating children with amphetamine derivatives, particularly methylphenidate. Although paediatricians and child psychiatrists who regularly prescribe methylphenidate for a carefully selected group of children with pervasive ADHD are convinced of its efficacy, its value and safety are unclear for children who are comorbid for autism or conduct disorders, or who have epilepsy, tics, or general learning difficulties. There is little consensus among experienced practitioners which is confusing for those they teach and for parents, anxious about long term psychotropic medication.

There have been no recent studies of long term stimulant treatment for ADHD and no double blind, placebo controlled trials, although clinicians sometimes use randomised blind placebo treatment for individual patients when treatment response is unclear. The study by Gillberg $e t$ $a l$ is a sound, important, and courageous study which involved denying children an effective treatment at a critical stage for their education and social development. The authors found it was difficult to remain blind because of the efficacy of the treatment. Only 8 of 30 patients continued to take the placebo after 6 months. As they dropped out the majority chose to receive amphetamines.

The study shows that non-responders and the few who experience unacceptable side effects can be identified soon after treatment starts. Comorbid patients, even those with autism and conduct disorder, responded equally well, although it would be interesting to know the response of children with more serious psychosocial problems who were excluded from the study. With 1 exception amphetamines did not make tics or epilepsy worse. In general there were minimal side effects, except for a reduction in appetite which did not appear to affect height. The benefits of medication were at least as marked at home as at school which suggests treatment should continue during weekends and holidays in this severe group. The long term effects were also more pronounced in the older group perhaps because they were less likely to improve with maturity.

Alyson Hall, MB, BS Royal London Hospital London, UK 